\title{
Copyright and the Perioperative Nurse
}

This manuscript version

is a rendition of

the author's post review copy.

The official version of record

is available at the

Perioperative Nursing Clinics site.
Nursing Informatics

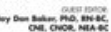

PERIOPERATIVE

NURSING

CUINICS

Helen Hough, MLS, BS, BA ${ }^{a}{ }^{*}$, Kristen Priddy, RNC-Ob, MSN, CNS ${ }^{b}$

\section{KEYWORDS}

- Copyright $\bullet$ Internet $\bullet$ Writing for publication $\bullet$ Teaching materials $\bullet$ Liability

\section{KEY POINTS}

- The authors or creators of products including written works, graphics, photographs, and digital objects have rights to determine how these products can be used.

- Permission to use the products of other people's creative endeavors should be obtained.

- Use of these products without permission can result in fines.

- There are several methods of protection against copyright liability.

Every time a perioperative nurse gives a patient printed instructions to take home, that nurse is involved with issues related to copyright. When a person makes photocopies to share with others, downloads a file or graphic to use at work, provides handouts at an in-service or a class, or writes for publication, the person is involved with copyright regulations. A basic understanding of why copyright exists, what it involves, and how it impacts the health care provider is important. Knowledge of the opportunities related to copyright fair use allows some flexibility. Failure to abide by copyright regulations can financially impact both the provider and the institution where the provider works. Using this knowledge can protect the nurse from lawsuits.

Stories are often heard about downloading online songs and movies and how easy this is to do. In addition, stories are related about how music or film companies try to prevent these downloads. The person who is trying to obtain useful resources may not appreciate why there is restricted access on some publications by the publisher

\footnotetext{
The authors have nothing to disclose.

Authors' Legal Statement: We are information and nurse professionals, not lawyers. This intellectual property information is provided for general purposes only. If you believe you have a legal concern, please contact a licensed legal professional. If you are associated with a government agency or corporation, also consider contacting your business's legal representation.

${ }^{\mathrm{a}}$ Science and Engineering Library, University of Texas at Arlington, PO Box 19497, B03 Nedderman Hall, 416 Yates Street, Arlington, TX 76019, USA

${ }^{b}$ College of Nursing, The University of Texas at Arlington, Box 19407, 622 Pickard Hall, 411 South

Nedderman Drive, Arlington, TX 76019, USA

* Corresponding author.

E-mail address: $\underline{\text { hough@uta.edu }}$
}

Perioperative Nursing Clinics 7 (2012) 201-210

doi:10.1016/j.cpen.2012.02.008 periopnursing.theclinics.com

(C) 2012 Elsevier Inc. All rights reserved. 
or owner when these things can be easy to see and copy from another venue. After all, how could these alternate copies affect these companies? Besides, with a slight bit of technical skill, downloading files or photocopying articles or books is often easy to do. What most people do not realize is that these actions may be in violation of the US Copyright Act ${ }^{1}$ and, depending on the circumstances, people and the companies they work for may be liable for inappropriate reproduction and distribution of materials owned by others.

As an exercise for understanding copyright, consider a car as a metaphor for a book, graphic, or song. A person can buy one or more cars or can buy one or more copies of a book or similar resource. That person owns those specific objects, not all copies of that object. The key to a specific car does not open all cars of the make and model. If a person attempts to manufacture more of those cars and sell them without permission from the original manufacturer, the lawyers at the company holding the right to manufacture those cars will probably seek financial reparations. The person who wants more of the cars has a few options including (a) buying, (b) formally borrowing, or (c) renting them from the manufacturer or dealer. The person could alternatively choose to buy similar cars from other manufacturers or build really nice, even better, new cars. Intellectual property in the form of words, music, and graphics is just as much property as are physical objects like cars. The ownership of a specific make and model of a car does not give a person the right to manufacture more of those cars, just as owning a book or painting does not give the right to that owner to make copies of that book or painting and distribute those copies. The person who has obtained one car or one copy of a book, painting, or other creative work has exactly that, one item. A person can own a car, text, or picture and keep, loan, rent, or sell that specific car, text, or picture, but not other copies of that product.

Ownership options fall within the copyright, trademark, or patent laws when an item is the result of intellectual property such as a person's ideas. Patents are related to inventions, and trademarks are related to images or text that represent an entity including a company or product. Copyright law is related to the ownership of text, music, presentations, and images fixed in tangible form. These forms include the physical object itself, print copies, or digital formats. Through the intellectual property laws, people own the products of their ideas and creations and have the right to determine how these products are made available to others.

\section{THE US CONSTITUTION}

In the United States, copyright is based on the US Constitution. It is not just within the Bill of Rights or the Amendments, but within the Constitution itself. Article $1^{2}$ defines the power of the US Congress. Section 8, Clause 8 of Article 1 states that Congress has the power "To promote the Progress of Science and useful Arts, by securing for limited Times to Authors and Inventors the exclusive Right to their respective Writings and Discoveries." ${ }^{2}$ From this statement comes the American intellectual property laws that Congress has passed, including the Digital Millennium Copyright Act. ${ }^{3}$ Over the past 2 centuries these laws have changed to reflect American social concerns and technological developments. Many other countries currently have similar laws, some more restrictive and others less restrictive than American laws. Of course, current technology enables the transmission of intellectual property, the tangible record of ideas, across international borders. It can be difficult to determine who created what and where it was created. However, the information about the ownership of things recorded as electronic files, printed resources, and images including pictures can also be transmitted across borders. The United States has treaties with many countries, 
and people who violate intellectual property laws can face legal problems in other countries.

Cultural variations in the values placed on ideas further complicate issues relating to intellectual property laws. In some cultures, the concept that a person or corporation can truly own the products of an idea is incomprehensible; good ideas are to be used to benefit members of the larger community. Even if the concept of the ownership of ideas is part of a person's worldview, there is often a lack of understanding of the difference between owning an object created as a result of that idea and having the right to distribute copies of that object. When tangible objects are a product of an idea, these products can be owned and controlled by the author or creator. A common result of the failure to understand both of these views, ownership of an idea or the objects that are created from them, is that there are many incidences of intellectual property theft. An example of intellectual theft often comes in the form of counterfeiting. Counterfeiting is defined as systematic copying of an image, object, product, or computer file without paying for it and the selling these copies as the original or a legitimate, registered, and faithful reproduction of the original concept. ${ }^{4}$ Sometimes the illegal copy is not as reliable as the appropriately manufactured product, as has been shown in counterfeit drugs. Sometimes the copy is perfectly acceptable but the owner/creator or copyright holder is not compensated for the skill and effort that went into the creation of the object; a book, painting, photograph, piece of art, computer program, or other material.

Another interesting analogy to paying for intellectual property is paying for health care. People who create things by writing, creating graphics, developing programs, and so on, learned how to do these activities. They spent time and money developing these skills, often over years. They usually earn their living by producing these resources. If creative work was easy, anyone could create high quality materials. The provision of high quality nursing care has similar features. Perioperative nurses and other health care providers spend years learning and developing the skills to provide valuable care. On the other hand, this care is expensive and many consumers do not want to pay the high costs related to this care. Just as nurses and other providers deserve reasonable compensation for their labors, authors and artists should be paid for theirs. Using resources without fairly compensating their creators does not respect the time, education, intellectual effort, or other costs associated with the resources. Only if the products of this time and labor are freely given should others feel free to take them.

\section{COPYRIGHT}

Copyrights are the rights provided to creators that allow them control regarding the use of their products of their intellectual efforts. These rights and privileges include the right to reproduce the work. Another right is the right to distribute the work, including creating print copies and distribution over the Internet or by other methods, including digital versions. An author or creator can also determine who can publicly perform certain types of works and where these performances are permitted, including publicly playing recordings. Permissions for use of materials still under copyright protection include the right to restrict public presentation of recordings. Only the author or creator has the right to allow others some or all of these privileges (Table 1). The author or creator can sell some or all of these privileges to others. These rights are usually transferred by contract, just like one would transfer ownership or allow the renting of a car. Both the creator and the recipient should keep copies of these contracts. 
Table 1

Copyright owner rights

\begin{tabular}{|ll}
\hline Right & Example \\
\hline Reproduce & Make a copy \\
\hline Create derivative work & Use a work as basis for new work \\
\hline Distribute work & Electronically distribute/publish copies \\
\hline Publicly perform work & Publicly perform \\
\hline Publicly play recording & Publicly play recordings \\
\hline Publicly display work & Publicly display image on computer screen \\
\hline Allow/contract others these rights & Permission to use, perform, or distribute \\
\hline
\end{tabular}

\section{AMERICAN COPYRIGHTABLE INTELLECTUAL PROPERTY}

American intellectual property includes traditional written products like text, plays, and musical scores. Artistic products including graphics, photos, and images are also intellectual property. Performances and recordings of these performances as well as other works including tests, assessment instruments, and computer programs are protected. Materials that are copyrighted are those works fixed in tangible form, meaning that the idea has been written, drawn, photographed, or otherwise recorded in any one of a variety of media including print and digital formats. A person can see or touch the object that is the result of the development of the idea. These products are copyrighted. Some ideas, processes, methods, and systems described in standard copyrighted works are not considered copyrighted.

Some things are not considered original creative works, including facts and works composed of these facts. Included also in the class of nonoriginal works are logical, comprehensive compilations like phone books. Other resources were never eligible for copyright protection, and others have passed the duration of protection in effect at the creation or registration of the resource or renewal of these rights. US federal government publications are not eligible for coverage because these are created with public funds; they are automatically within the public domain. Government agencies may use some materials with permission of the creators and without compromising the owners' reproduction rights; examples of this use can include the A.D.A.M. graphics, which are often used in MedlinePlus Web pages. ${ }^{5}$ A.D.A.M. Inc has retained the right to sell these graphics even though the graphics are used in government publications. State and local government agency resources are copyright protected because they are not federal documents.

Copyright privileges exist for limited periods, as indicated in the US Constitution. ${ }^{1}$ Materials are in the public domain when copyright protections do not exist for the author or creator of that object. Some products have never been protected, including most federal government publications, whereas other products lapse into the public domain after specific periods. These periods are governed by the copyright laws in existence at the time of the creation or registration of the resource, by renewal of these rights by the owners, or as otherwise indicated by law.

Owners or creators can also choose to expressly donate their creative works to the public. An example of these donated creative works is freeware, which the author has chosen to make available without restriction. Other limited donated works may be identified by Creative Commons (CC) licensure or other open access initiatives. ${ }^{6,7}$ $\mathrm{CC}^{6}$ is a nonprofit organization that advocates and supports legal and technical methods that increase creativity and sharing of digital resources. One of these 
methods is the CC copyright license. The CC licenses have a structure that allows the creator/author of digital works to clearly specify how these works may be used by others including copying, distribution, editing, and remixing. Open access is an international movement among scholars and researchers to provide quality research materials at low or no cost to the reader. An example of one of the leading organizations in this movement is the Scholarly Publishing and Academic Resources Coalition (SPARC). ${ }^{7}$ Many colleges, universities, and research institutions have institutional repositories where members of the organization can deposit copies of their works so the public can access them.

Scholars may be required to sign over their copyrights to publishers as a part of the publication process. Often authors sign contracts without realizing the contract allows the publisher to become the copyright holder and the author no longer has any rights to the creative work. Contracts between author and publisher may be modified by the participants of the contract. A common modification is the SPARC author addendum, which includes reserving the right to keep a copy of the work in the author's institutional repository. ${ }^{8}$ The author addendum can also allow the author to use these works in classes he or she teaches. Licensed legal experts in copyright law are best able to interpret what materials might be copyrighted, what cannot be protected, and which materials are no longer protected.

\section{LEGAL CONSEQUENCES}

Individuals and companies may make significant money on copyrighted materials. At the very least, there are authors, illustrators, programmers, and people in publishing, music, and movie industries who make their living as a result of creative efforts. Copyright infringement, like stealing cars, can have expensive repercussions. If a charge of willful copyright infringement is shown true in an American court, currently a fine of up to $\$ 150,000$ for each act can be rendered in addition to attorneys' fees and other legal costs. Willful infringement means the person knew about copyright and violated it anyway. Unintentional infringement is usually limited to damage (loss of income) as well as the attorneys' and other legal fees. Either intentional or unintentional infringement can result in significant costs to the person who violated these laws. As in the case of malpractice suits, social and emotional costs are high even if the defendant is found innocent.

\section{WHAT IS COPYRIGHT PROTECTED?}

US copyright applies to United States materials and those created or registered in countries with which the United States has treaties. ${ }^{1}$ As of 2011, materials published prior to 1923 are in public domain and may be used freely (Table 2). Materials published between 1923 and 1963 that are marked with the copyright symbol are in the public domain if the copyrights have not been renewed. Materials published between these two dates and formally renewed are still protected. The oldest currently copyrighted materials will go into public domain in 2019 unless Congress changes the law and extends these rights. An extension was granted to materials published between 1964 and 1978 because Congress extended copyright protection periods. Materials published between 1964 and 1978 were eligible for automatic renewal and are still under copyright.

Materials created after 1978, whether formally published or not, are copyright protected for the life of the author/creator plus 70 years. In other words, it does not matter if a book, painting, photograph, graphic, computer program, audio recording, video recording, or personal diary is old by someone's definition of old. Old enough is defined 


\begin{tabular}{|c|c|c|}
\hline \multicolumn{3}{|c|}{$\begin{array}{l}\text { Table } 2 \\
\text { Copyright protection time period }\end{array}$} \\
\hline Published & Copyright Length & Public Domain \\
\hline Before 1923 & Now in public domain & Yes \\
\hline 1923_1963, not renewed ${ }^{a}$ & $28 \mathrm{y}$, with (c) & Maybe \\
\hline 1923_1978, renewed ${ }^{a}$ & $95 \mathrm{y}$, with $\odot$ & No \\
\hline After 1978 & Life of author/creator_ $70 \mathrm{y}$ & No \\
\hline Never published & Life of author/creator_ $70 \mathrm{y}$ & No \\
\hline
\end{tabular}

by current copyright law. It does not matter if these objects have copyright symbols on them or not. The symbol is not currently required. Many things can still be under copyright. If materials have been created within the past 30 years, simply the act of creating them entitles the authors/creators the copyright privileges associated with those products.

\section{EDUCATIONAL/FAIR USE}

There is a little flexibility in the copyright law for commentary about intellectual property as well as educational and research use of these products. Most of this flexibility, called fair use, is based in physical in-class use, student use, individual use, and use within limited collaborative research venues. Online courses are more restricted because of the course distribution method. Posting products on the Internet can cause multiple copies to be easily created and accessed. Without care by the person posting the document, image, or file, an Internet environment can unintentionally allow people from around the world access to the protected material. This lack of care can result in the person posting the item being at risk for either intentional or unintentional copyright infringement, depending on the circumstances. People are not legally authorized to copy and post text or graphics on the Internet, even if this posting is for a class of patients, a class of students, or for some other worthy purpose. The TEACH Act clarifies and provides additional limitations related to copyright for online course work. ${ }^{9}$

\section{FAIR USE FOUR FACTORS}

Interpretation of fair use as it relates to copyright can be complicated. The current United States copyright laws are old enough to be nonspecific relative to technological advances, and the courts have not provided consistent interpretations. Some courts have favored educational use, and others have leaned toward favoring the copyright owner, particularly when the owner is a company or corporation that has suffered economic damage from copyright infringement.

Generally, there are four factors (Table 3) weighing in on fair use, all of which are related to money. ${ }^{10}$ These factors are the (a) character of the use, (b) nature of the work, (c) percentage of the work being used, and (d) marketability of the material. The character of the use is associated with how materials are being used.

Character of use is judged in the context of material being used in a nonprofit, educational, or personal setting (Box 1). A consideration, even in a nonprofit or educational setting, is that people may be earning money as a result of this use. Even 


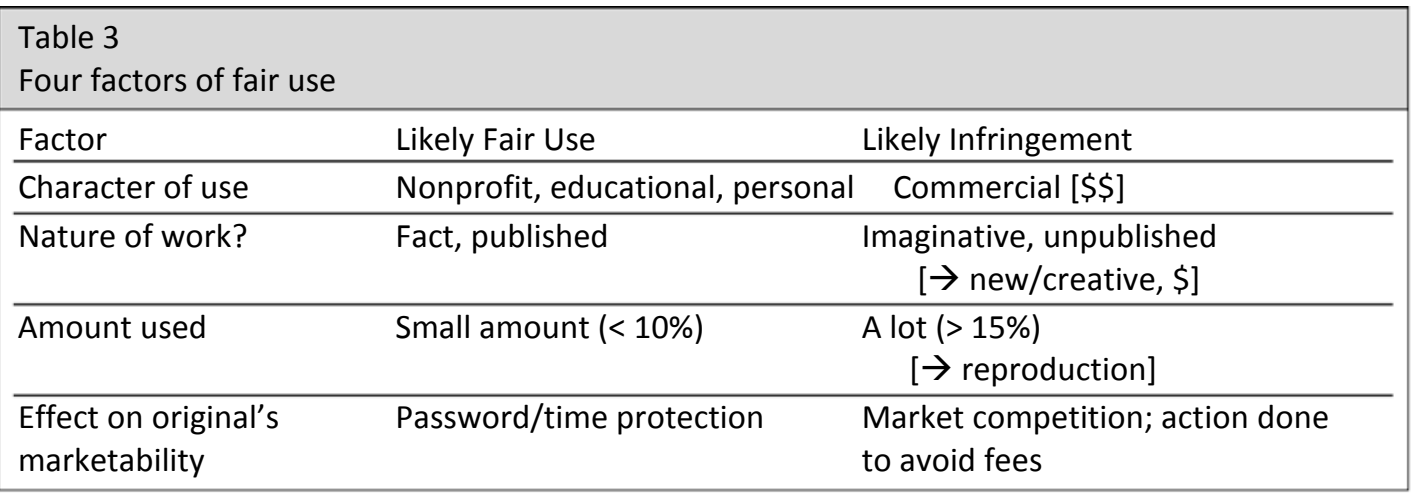

in a nonprofit or educational setting, doctors, nurses, health care providers, teachers, and many others are getting paid and therefore misusing copyrightable materials, resulting in earnings from someone else's idea and labor.

The second factor, the nature of the work or material, is that a fact, set of facts, or materials already published may be easily available. Weighing against ease of access is that some materials are the result of creative endeavors that cannot be produced by just anyone. The material may be unpublished and the author/creator may be able to earn some income as a result of documenting these ideas.

The amount of copyright materials used is also considered. A small amount, usually less than $10 \%$ of the entire work, is often considered negligible. This negligible amount is not usually a problem. More than $15 \%$ of an entire work, or in the case of something like a book or a movie, the disclosure of full plot line or conclusion might be considered infringement. A consideration with objects like graphics is that whereas the object itself may be small, it is the percentage of use of that object that is evaluated, not the size of the object. One cannot copy and use an entire graphic because the entire graphic is the entire work.

Often the most significant factor is the effect on the marketability of the material. There may be less liability in a court of law for the person or corporation distributing copyrighted materials without permission if access to material is controlled by password and/or time constraints. Most courts will probably not look favorably at a person or company engaging in the distribution of copyrighted materials, even in restricted environments, if the intention of the distribution is to avoid paying fees for the use of the material.

\section{PLAGIARISM}

Plagiarism is related to but may not constitute copyright infringement. Plagiarism may be considered fraud. If a person presents prior work or knowledge from someone else's work as new or one's own, this representation is not truthful. If the person is

\section{Box 1}

Copyrighted materials

- Creative efforts fixed in tangible forms including text, images, and digital formats

- Potentially income-generating

- Constitutionally based rights 
presenting this work for academic credit, monetary reward, or purposes of prestige, the person is misrepresenting his or her abilities. In academic and scientific environments such as hospitals, this presentation is called plagiarism. Even self-plagiarism can occur if older work is submitted as new. The author/creator may own the work, and it is the misrepresentation of the materials that is the problem. When discussing previously published or submitted materials, the author or creator should document these facts in any new materials.

\section{LIKELIHOOD OF BEING CAUGHT}

Cases of copyright violation have not been that common in courts of law. Most court cases are expensive, and violations are commonly settled out of court. The copyright holder may ask the person engaging in violation of the holder's right to stop distributing materials however the distribution is determined. Often the violator will stop. Cases are brought to court when the risk of losing income outweighs the cost of trial. The liability of copyright infractions goes beyond an individual. Companies and institutions are more likely to be brought to court than are specific individuals. The company or agency is brought to court for permitting the violation to occur. A perioperative nurse might make an error regarding how materials are used during in-service instruction, in patient education, or on institutional Web sites. Single individuals have been pursued when a professional organization chose to make a public example of the consequences of copyright violation. The safest thing to do is protect yourself with knowledge; know what copyright is, the rights of the specific products with which you are working, and any contracts associated with the use or distribution of these creative works. Keep copies of correspondence and any contracts you have signed.

\section{WAYS TO PROTECT YOURSELF}

The first thing to do when using someone else's work is ensure that it is allowed that the material be used in this new way. Contact the copyright holder and ask for permission for this use. If a CC license is identified, check the license for the specific uses permitted. ${ }^{4}$ Keep copies of these permissions in case any questions arise. Recall the analogy of the car in attempting to use text, graphics, or programs that have been seen on the Internet. People can look at someone's car but need permission to drive it. Just because something is viewable on the Internet does not imply that other people can copy the resource. Ability to look at a graphic on the Internet does not include right to copy and reuse it. Owning a book allows people to have a book, not reproduce the content. Subscribing to a journal or current awareness service allows the subscriber the use of the product as specified by subscription service. Check the contracts for these services. Honest and reasonable attempts to locate the owner/ creator of materials should occur if materials are found on the Internet and someone wants to copy and reuse those materials. Do not use materials that do not have explicit permissions for this new use. If reuse is on the Internet, often linking instead of copying is sufficient, because linking is not copying and redistribution.

Linking permits the owner/creator to maintain control of the distribution of the material. If the material is simply linked and not copied and the owner decides not to allow this reuse, the owner can choose to remove the original object. As a linked object, if the owner removes the original, the link is broken and the material is no longer available on the secondary site. Linking to an object maintains the rights of the copyright holder to reproduce, distribute, and display the work as he or she sees fit. 
Check the license on computer graphics or other image resources. Just because some graphics are part of a computer program does not mean that reproducing these graphics is permissible. There are some cases where graphics may have been included with purchased software but permission to use these graphics in public forums is not included. Check the contract included with the software or on the product's Web site. If necessary, contact the copyright holder or software company for clarification. Keep copies of these communications. If permissions are not given, consider searching the Internet for similar graphics that are available for use. Creative people (perioperative nurses) can, of course, develop their own.

Photographers hold the copyright for their photographs. The individuals or institutions in the photographs do not have copyright privileges. A health care institution has obligations to protect the privacy of patients and children. An organization may also limit access to items and how the identifiable components are portrayed. Individuals who are photographed may have other options regarding how they are portrayed in these photographs, such as restricting the use to within the hospital for educational purposes only but not beyond that function. Access and portrayals are not related to copyright but rather fall under privacy, trademark, trespass, slander, libel, or other laws. If you are photographing people or physical property for distribution, consider asking permission to do so and keeping copies of these permissions. If you are using someone else's photographs, ensure that you have permission for that use and the use respects the additional laws.

Fair use may permit someone doing a presentation to use graphics and other materials that enhance the presentation. The presentation may fit within the fair use educational use factor. Change the format of any handouts to include only the text and do not include clip art or other components of the presentation software. The handouts are for reproduction and distribution. If graphics from nursing textbooks or articles are necessary components, consider obtaining permission to use these graphics.

Sharing articles with a few colleagues or posting a copy on a bulletin board is probably reasonable. Copying an article for a specific patient is also probably reasonable. Reproducing articles or standards of practice for each person in a class, in-service session, group of patients, or research group may be in copyright violation. Consider providing instructions on how these materials may be obtained by the individuals. Buying reprints for distribution is also an option.

\section{SUMMARY}

Copyright laws and regulations are complex and have changed over time. There can be significant costs of not recognizing or disregarding these laws. Care in ensuring appropriate use of creative works and keeping documentation can protect the user from some of the risks. There are initiatives to ease the burden of care, increase access to valuable knowledge, and share creative works. CC licenses, open access initiatives, and generous creative people are part of these initiatives. ${ }^{6,7}$ Consider participating in these initiatives when engaging in creative efforts. When publishing articles, read the author contract and consider author addendums.

\section{REFERENCES}

1. US Copyright Office. Copyright law of the United States and related laws contained in Title 17 of the United States Code [circular 92]. Available at: http://www.copyright. gov/title17/. Accessed March 13, 2012.

2. US Constitution, Art $1, \operatorname{Sec} 8$, Clause 8. 
3. US. Copyright Office. Appendix B. The Digital Millennium Copyright Act of 1998. Available at: http://www.copyright.gov/title17/92appb.pdf. Accessed March 13, 2012.

4. Copyright. In S. Phelps, J. Lehman, editors. West's encyclopedia of American law, vol. 3. 2nd edition. Detroit (MI): Gale; 2005. p. 190-200.

5. US National Library of Medicine. Copyright information. Published September 2011. Available at: http://www.nlm.nih.gov/medlineplus/copyright.html. Accessed March 13, 2012.

6. Creative Commons. About. Available at: http://creativecommons.org/about. Accessed March 13, 2012.

7. What is SPARC? Scholarly Publishing and Academic Resources Coalition. Available at: http://www.arl.org/sparc/about/index.shtml. Accessed March 13, 2012.

8. SPARC. Author rights: using the SPARC author addendum to secure your rights as the author of a journal article. Published summer 2006. Available at: http://www. arl.org/sparc/author/addendum.shtml. Accessed March 13, 2012.

9. Harper GK. The TEACH Act Copyright Crash Course. Published 2007. Available at: http://copyright.lib.utexas.edu/teachact.html. Accessed March 13, 2012.

10. Harper GK. Fair use of copyrighted materials Copyright Crash Course. Published 2007. Available at: http://copyright.lib.utexas.edu/copypol2.html. Accessed March 13, 2012. 